\title{
Thermal expansion of $\mathrm{Pb}_{2} \mathrm{P}_{2} \mathrm{Se}_{6}$ crystals
}

\author{
${ }^{1}$ Mys O., ${ }^{2}$ Girnyk I., ${ }^{3}$ Grabar A., ${ }^{1}$ Martynyuk-Lototska I., ${ }^{1}$ Kostyrko M. and \\ ${ }^{1}$ Vlokh R. \\ ${ }^{1}$ Institute of Physical Optics, 23 Dragomanov Street, 79005 Lviv, Ukraine, \\ vlokh@ifo.lviv.ua \\ ${ }^{2}$ Scientific-Technical and Educational Center of Low-Temperature Studies, Ivan \\ Franko National University of Lviv, 50 Dragomanov Street, 79005 Lviv, Ukraine \\ ${ }^{3}$ Institute for Solid State Physics and Chemistry, Uzhgorod National University, 54 \\ Voloshyn Street, 88000 Uzhgorod, Ukraine
}

Received: 09.10 .2013

\begin{abstract}
We present the results for thermal expansion coefficients of $\mathrm{Pb}_{2} \mathrm{P}_{2} \mathrm{Se}_{6}$ crystals determined in a wide temperature range both in the crystallographic system and in the coordinate system based on eigenvectors of thermal expansion tensor. The thermal expansion coefficients of $\mathrm{Pb}_{2} \mathrm{P}_{2} \mathrm{Se}_{6}$ are almost independent of temperature, thus making the crystals suitable for many applications.
\end{abstract}

Keywords: $\mathrm{Pb}_{2} \mathrm{P}_{2} \mathrm{Se}_{6}$ crystals, thermal expansion, anisotropy

PACS: $65.40 . \mathrm{De}, 78.20 . \mathrm{Hp}$

UDC: $669.018 .47+681.7 .03$

\section{Introduction}

$\mathrm{Pb}_{2} \mathrm{P}_{2} \mathrm{Se}_{6}$ crystals are representatives of a family of wide-gap, low-symmetry semiconductors with a general formula $\left(\mathrm{Sn}_{1-\mathrm{y}} \mathrm{Pb}_{\mathrm{y}}\right)_{2} \mathrm{P}_{2}\left(\mathrm{Se}_{\mathrm{x}} \mathrm{S}_{1-\mathrm{x}}\right)_{6}[1,2]$. Tin-containing solid solutions $\mathrm{Sn}_{2} \mathrm{P}_{2}\left(\mathrm{Se}_{\mathrm{x}} \mathrm{S}_{1-\mathrm{x}}\right)_{6}$ undergo a proper paraelectric-to-ferroelectric phase transition, with the change of point symmetry group $2 / \mathrm{m} \mathrm{F} \mathrm{m}$. Besides, the mixed crystals with a predominant concentration of selenium manifest an incommensurately modulated phase between their paraelectric and ferroelectric phases $[1,2]$. Pure $\mathrm{Pb}_{2} \mathrm{P}_{2} \mathrm{~S}_{6}$ and $\mathrm{Pb}_{2} \mathrm{P}_{2} \mathrm{Se}_{6}$ crystals exhibit no structural phase transitions down to liquidhelium temperature and belong to the point symmetry group $2 / \mathrm{m}$.

Crystals of $\left(\mathrm{Sn}_{1-\mathrm{y}} \mathrm{Pb}_{\mathrm{y}}\right)_{2} \mathrm{P}_{2}\left(\mathrm{Se}_{\mathrm{x}} \mathrm{S}_{1-\mathrm{x}}\right)_{6}$ family can be efficiently used in different branches of optoelectronics. At least, $\mathrm{Sn}_{2} \mathrm{P}_{2} \mathrm{~S}_{6}$ is known as efficient electrooptic [3-5] and photorefractive [6, 7] material. Its electrooptic coefficient $\left(r_{11}=1.74 \times 10^{-10} \mathrm{~m} / \mathrm{V}\right.$ for the room temperature and the light wavelength of $\lambda=633 \mathrm{~nm}$ [3-5]) is two orders of magnitude higher than that of many commonly known electrooptic materials. Recently we have also shown that $\mathrm{Sn}_{2} \mathrm{P}_{2} \mathrm{~S}_{6}$ and $\mathrm{Sn}_{2} \mathrm{P}_{2}\left(\mathrm{~S}_{0.72} \mathrm{Se}_{0.28}\right)_{6}$ reveal high enough acoustooptic figures of merit $\left(\sim 1700 \times 10^{-15} \mathrm{~s}^{3} / \mathrm{kg}\right.$ [8-10]). Notice that the normal conditions are very close to the phase transition points in these crystals $\left(T_{C}=337 \mathrm{~K}\right.$ for $\mathrm{Sn}_{2} \mathrm{P}_{2} \mathrm{~S}_{6}$ crystals and $T_{C}=284 \mathrm{~K}$ for the solid solutions $\left.\mathrm{Sn}_{2} \mathrm{P}_{2}\left(\mathrm{~S}_{0.72} \mathrm{Se}_{0.28}\right)_{6}\right)$. This hinders applications due to possible temperature variations of working parameters caused by tricritical temperature behaviour. On the other hand, the $\mathrm{Pb}_{2} \mathrm{P}_{2} \mathrm{~S}_{6}$ and $\mathrm{Pb}_{2} \mathrm{P}_{2} \mathrm{Se}_{6}$ crystals have no structural phase transitions. As shown in our recent works $[11,12]$, the thermal expansion coefficients of $\mathrm{Pb}_{2} \mathrm{P}_{2} \mathrm{Se}_{6}$ are almost temperature-independent in the vicinity of the room temperature, while the acoustooptic figure of merit estimated to be high enough $\left(\sim 500 \times 10^{-15} \mathrm{~s}^{3} / \mathrm{kg}\right)$. However, in the works $[11,12]$

Ukr. J. Phys. Opt. 2013, Volume 14, Issue 4 
the thermal expansion has been studied only for a narrow temperature interval $(350-410 \mathrm{~K})$, whereas the anisotropy of the property has not been analyzed in sufficient detail. Probably, $\mathrm{Pb}_{2} \mathrm{P}_{2} \mathrm{Se}_{6}$ crystals are the least studied among the compounds of $\left(\mathrm{Sn}_{1-\mathrm{y}} \mathrm{Pb}_{\mathrm{y}}\right)_{2} \mathrm{P}_{2}\left(\mathrm{Se}_{\mathrm{x}} \mathrm{S}_{1-\mathrm{x}}\right)_{6}$ family. It is known that these monoclinic crystals are optically biaxial and transparent mainly in the infrared range, with the absorption edge corresponding to the wavelength $\sim 591 \mathrm{~nm}[13]$.

The goal of the present work is to study experimentally the thermal expansion of $\mathrm{Pb}_{2} \mathrm{P}_{2} \mathrm{Se}_{6}$ crystals for a wider temperature range and analyze its anisotropy.

\section{Experimental method}

The thermal expansion of $\mathrm{Pb}_{2} \mathrm{P}_{2} \mathrm{Se}_{6}$ crystals $\left(\Delta L_{i} / L_{j}^{0}=\left(L_{i}-L_{i}^{0}\right) / L_{j}^{0}\right.$, with $L_{i}^{0}$ denoting the initial linear size of a sample along axis $i$ and $L_{i}$ its thermally induced size) was measured using an automated quartz dilatometer, with a capacitive displacement sensor providing the sensitivity of $2 \mathrm{~nm}$ at $90-530 \mathrm{~K}$. The measurements were carried out with the temperature scan rate of $0.5 \mathrm{~K} / \mathrm{min}$ in the heating run.

Since $\mathrm{Pb}_{2} \mathrm{P}_{2} \mathrm{Se}_{6}$ belongs to a monoclinic class, its crystallographic coordinate system is not orthogonal, though the deviation from orthogonality of $a$ and $c$ axes is small enough (1.33 deg [13]). We have neglected this nonorthogonality and below refer to the crystallographic coordinate system $a, b, c$ as to the orthogonal one. The lattice parameters at the room temperature and the atmospheric pressure are as follows: $a=6.606 \AA, b=7.464 \AA, c=11.3346 \AA$, and $\beta=91.33 \mathrm{deg}$ [13]. The $b$ axis is perpendicular to the symmetry mirror plane.

$\mathrm{Pb}_{2} \mathrm{P}_{2} \mathrm{Se}_{6}$ crystals were grown with a Bridgman technique at the Uzhgorod National University (Ukraine). We prepared two samples in the shape of parallelepipeds, with the dimensions of $5 \times 5 \times 5 \mathrm{~mm}^{3}$ and flat parallel faces perpendicular to $a, b$ and $c$ axes, and parallel to the bisector of $a$ and $c$ axes. The error for determination of the thermal expansion coefficients was about $5 \times 10^{-6} \mathrm{~K}^{-1}$.

In the crystallographic coordinate system, a second-rank tensor of the thermal expansion coefficients defined as

$$
\alpha_{i j}=\frac{\partial\left(\Delta L_{i} / L_{j}^{0}\right)}{\partial T}
$$

acquires the following structure for the point group $2 / \mathrm{m}$ :

$$
\alpha_{i j}=\left|\begin{array}{ccc}
\alpha_{a a} & 0 & \alpha_{a c} \\
0 & \alpha_{b b} & 0 \\
\alpha_{a c} & 0 & \alpha_{c c}
\end{array}\right| .
$$

Let us introduce the coordinate system, whose axes $X, Y$ and $Z$ coincide with the eigenvectors of the thermal expansion tensor, and $Y$ axis is parallel to the crystallographic $b$ axis. For conciseness, we refer to it as the eigen coordinate system. In this system we have the tensor

$$
\alpha_{i j}^{\prime}=\left|\begin{array}{ccc}
\alpha_{11}^{\prime} & 0 & 0 \\
0 & \alpha_{22}^{\prime} & 0 \\
0 & 0 & \alpha_{33}^{\prime}
\end{array}\right|,
$$

where $\alpha_{b b}=\alpha_{22}^{\prime}$. Once the thermal expansions along all the crystallographic directions are studied experimentally, the $\alpha_{i j}^{\prime}$ coefficients may be calculated by solving the system of equations 


$$
\left\{\begin{array}{l}
\alpha_{a a}=\alpha_{11}^{\prime} \cos ^{2} \Theta+\alpha_{33}^{\prime} \sin ^{2} \Theta \\
\alpha_{c c}=\alpha_{11}^{\prime} \sin ^{2} \Theta+\alpha_{33}^{\prime} \cos ^{2} \Theta \\
\alpha_{a c}=\alpha_{11}^{\prime} \sin ^{2}\left(\Theta+45^{\circ}\right)+\alpha_{33}^{\prime} \cos ^{2}\left(\Theta+45^{\circ}\right)
\end{array} .\right.
$$

In formulae (4), $\alpha_{a c}$ means the thermal expansion coefficient determined for the case of elongation along the bisector of $a$ and $c$ axes, and $\Theta$ is the angle in the plane $Z X$ between the $Z$ axis of the eigensystem and the direction along which the thermal expansion is measured. This angle is nothing but the angle between $Z$ axis of eigen coordinate system and $c$ axis of crystallographic system (see Fig. 1).

The data processing involved the following steps: interpolation of temperature dependences of the relative elongations and calculations of temperature derivatives for evaluating the expansion coefficients; interpolation and smoothing of temperature dependences of the thermal expansion coefficients associated with the crystallographic system. Then we calculated the coefficients for the eigensystem, the volume expansion coefficients and the angle between the eigensystem and the crystallographic one. The volume expansion coefficient was calculated using the formula

$$
\alpha_{V}=\alpha_{11}^{\prime}+\alpha_{22}^{\prime}+\alpha_{33}^{\prime} \text {. }
$$

The indicative surface describing spatial anisotropy of the thermal expansion tensor was calculated using formula $\alpha^{\prime}=\alpha_{i j}^{\prime} l_{i} l_{j}$, where $l_{1}=\sin \Theta \cos \varphi, l_{2}=\sin \Theta \sin \varphi$ and $l_{3}=\cos \Theta$, and $\Theta$ and $\varphi$ are the angles between the $Z$ and $X$ axes and a current spatial direction, respectively.

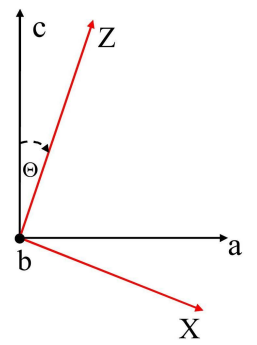

Fig. 1. Schematic representation of crystallographic system $(a b c)$ and eigensystem ( $X Y Z$ ) of the thermal expansion tensor.

\section{Results and discussion}

As seen from Fig. 2, a, the relative elongations for $\mathrm{Pb}_{2} \mathrm{P}_{2} \mathrm{Se}_{6}$ crystals depend linearly on temperature for all the crystallographic directions. This gives temperature-independent thermal expansion coefficients in the range under study (see Fig. 2,b).
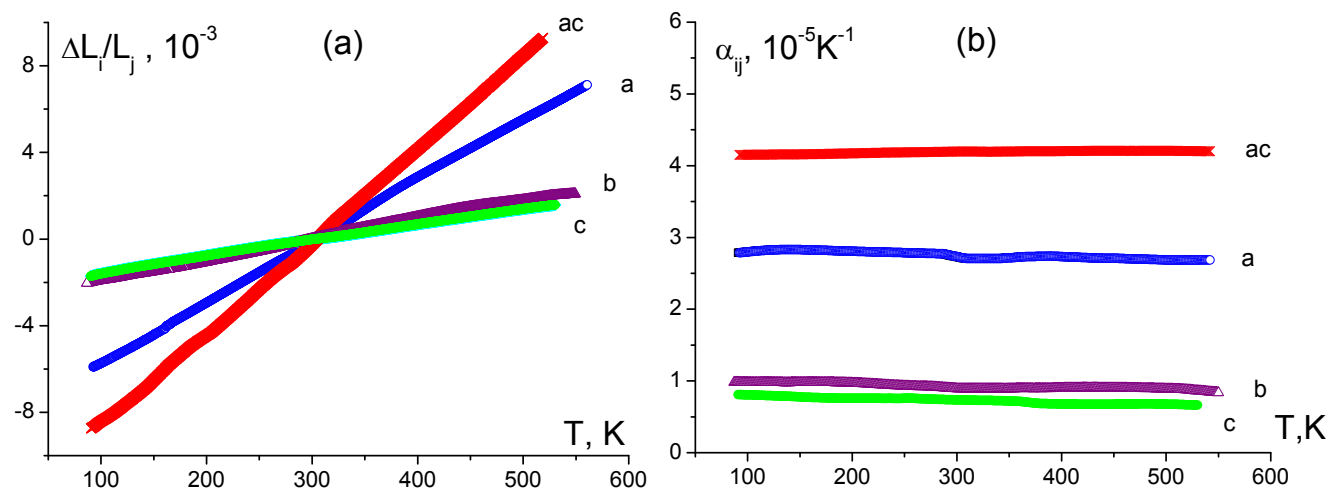

Fig. 2. Temperature dependences of relative elongations (a) and thermal expansion coefficients (b) of $\mathrm{Pb}_{2} \mathrm{P}_{2} \mathrm{Se}_{6}$ crystals for the axes a (open circles), $b$ (open triangles), $c$ (full circles), and the direction inclined by 45 deg with respect to the $a$ and $c$ axes (crosses).

Ukr. J. Phys. Opt. 2013, Volume 14, Issue 4 
All the thermal expansion coefficients determined in the crystallographic system are positive. The linear expansion coefficients recalculated for the eigensystem, the angle between the crystallographic system and the eigensystem, and the volume expansion coefficient are temperature independent, too (see Fig. 3).
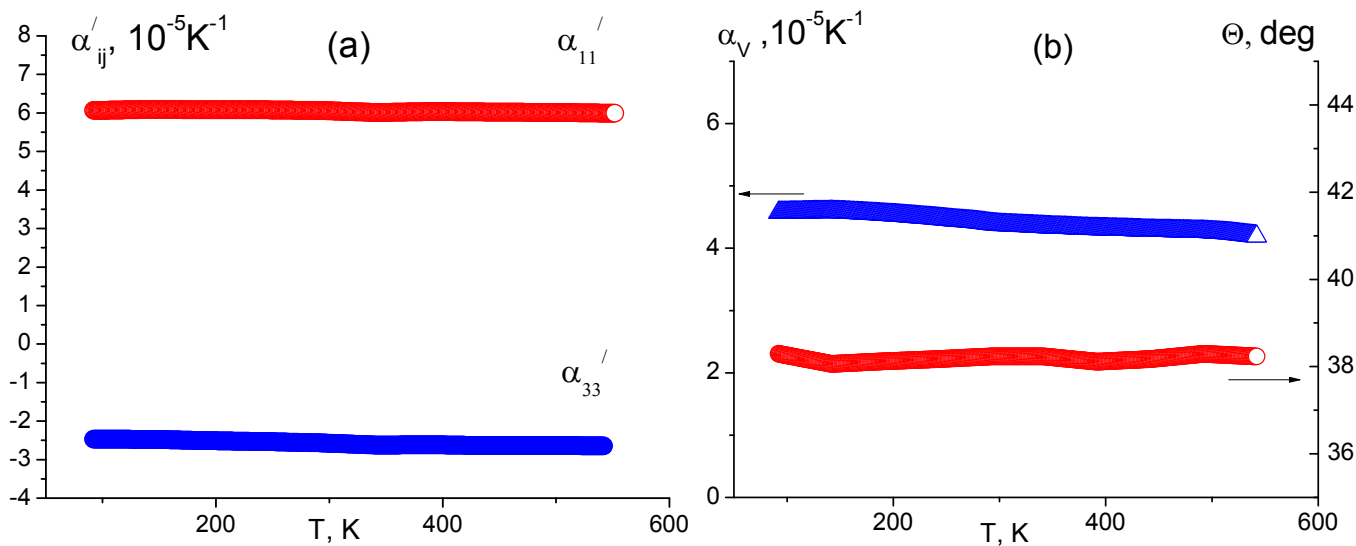

Fig. 3. Temperature dependences of (a) thermal expansion coefficients $\left(\alpha_{11}^{\prime}-\right.$ open circles and $\alpha_{33}^{\prime}-$ full circles), (b) the angle $\Theta$, and volume thermal expansion coefficient $\alpha_{V}$ for $\mathrm{Pb}_{2} \mathrm{P}_{2} \mathrm{Se}_{6}$ crystals.

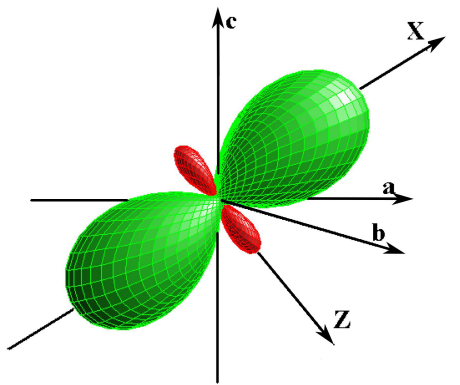

(a)

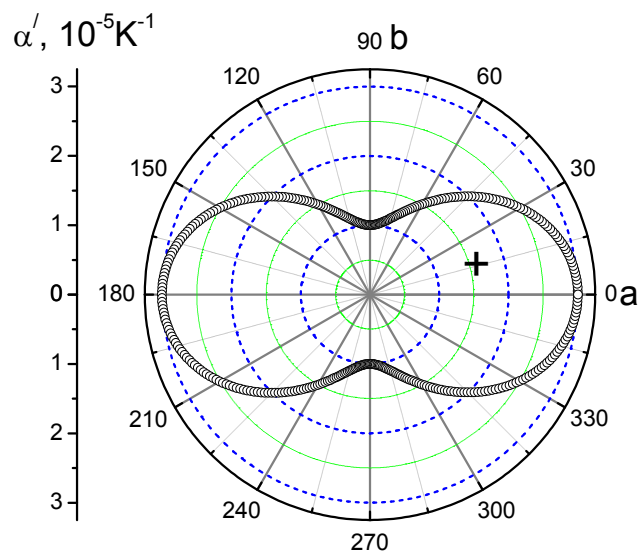

(c)

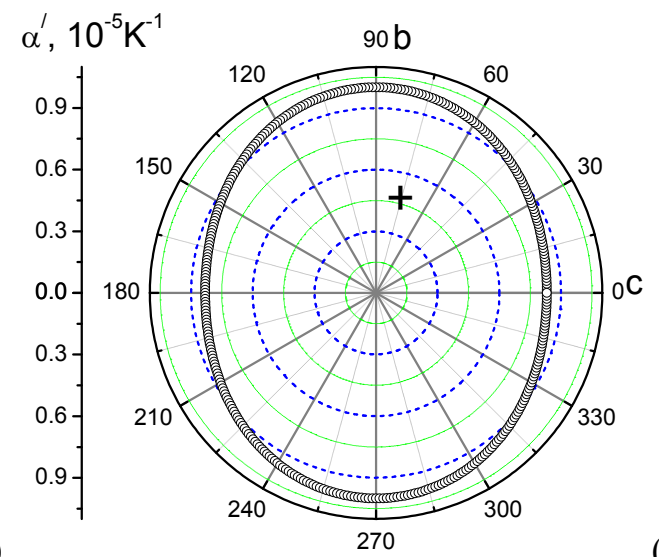

(d)

Fig. 4. Indicative surface of thermal expansion tensor for $\mathrm{Pb}_{2} \mathrm{P}_{2} \mathrm{Se}_{6}$ crystals (a) and its sections by the crystallographic planes (b, c, and d) at $T=293 \mathrm{~K}$. 
The indicative surface of the thermal expansion tensor and its cross sections are shown in Fig. 4. $\alpha_{33}^{\prime}$ is negative, while $\alpha_{11}^{\prime}$ and $\alpha_{22}^{\prime}$ are positive. The $\alpha_{33}^{\prime}$ and $\alpha_{22}^{\prime}$ coefficients are the smallest $\left(-2.57 \times 10^{-5} \mathrm{~K}^{-1}\right.$ and $0.89 \times 10^{-5} \mathrm{~K}^{-1}$, respectively). The coefficient $\alpha_{11}^{\prime}$ is equal to $6.06 \times 10^{-5} \mathrm{~K}^{-1}$ and the volume expansion coefficient is $4.4 \times 10^{-5} \mathrm{~K}^{-1}$. The latter is almost the same as the parameter for $\mathrm{Sn}_{2} \mathrm{P}_{2} \mathrm{~S}_{6}$ and $\mathrm{Sn}_{2} \mathrm{P}_{2}\left(\mathrm{Se}_{0.28} \mathrm{~S}_{0.72}\right)$ crystals inside their paraelectric phase, though much smaller than that in the vicinity of the phase transition point $[14,15]$.

The indicative surface is rotated clockwise by $38 \mathrm{deg}$ in the $a c$ plane with respect to the crystallographic system (see Fig. 3 and Fig. 4). The directions for which the thermal expansion is zero are given by the angles 111, 174, 291 and $354 \mathrm{deg}$ in the $a c$ plane. Moreover, the thermal expansion is negligibly small in all the $Y Z$ plane. Notice that the thermal expansion coefficients for $\mathrm{Pb}_{2} \mathrm{P}_{2} \mathrm{Se}_{6}$ are an order of magnitude smaller than those for $\mathrm{Sn}_{2} \mathrm{P}_{2} \mathrm{~S}_{6}$ and $\mathrm{Sn}_{2} \mathrm{P}_{2}\left(\mathrm{Se}_{0.28} \mathrm{~S}_{0.72}\right)$, in particular in the vicinity of phase transitions in those compounds [14, 15]. This makes $\mathrm{Pb}_{2} \mathrm{P}_{2} \mathrm{Se}_{6}$ crystals suitable for applying as working elements of different optoelectronic devices, in particular acoustooptic ones.

\section{References}

1. Slyvka V Yu and Vysochanskii Yu M, Ferroelectrics of $\mathrm{Sn}_{2} \mathrm{P}_{2} \mathrm{~S}_{6}$ Family. Properties around the Lifshitz Point. Uzhgorod: Zakarpattya, (1994).

2. Vysochanskii Y M, Janssen T, Currat R, Folk R, Banys J, Grigas J and Damulionis V, Phase Transitions in Ferroelectric Phosphorous Chalcogenide Crystals. Vilnius: Vilnius University Publishing House, (2006).

3. Vlokh R O, Vysochanskii Yu M, Grabar A A, Kityk A V and Slivka V Yu, 1991. Electrooptic effect in $\mathrm{Sn}_{2} \mathrm{P}_{2} \mathrm{~S}_{6}$ ferroelectrics. Izv. Akad. Nauk SSSR, Ser. Neorg. Mater. 27: 689-692.

4. Haertle D, Caimi G, Haldi A, Montemezzani G, Günter P, Grabar A A, Stoika I M and Vysochanskii Yu M, 2003. Electro-optical properties of $\mathrm{Sn}_{2} \mathrm{P}_{2} \mathrm{~S}_{6}$. Opt. Commun. 215: 333-343.

5. Say A, Mys O, Adamenko D, Grabar A, Vysochanskii Yu, Kityk A and Vlokh R, 2010. Critical exponents of phase transition in ferroelectric $\mathrm{Sn}_{2} \mathrm{P}_{2} \mathrm{~S}_{6}$ : comparison of optical and dilatometric data. Phase Trans. 83: 123-139.

6. Odoulov S G, Shumelyuk A N, Hellwig U, Rupp R, Grabar A A and Stoyka I M, 1996. Photorefraction in tin hypothiodiphosphate in the near infrared. Opt. Soc. Am. B 13: 23522360.

7. Jazbinsek M, Montemezzani G, Gunter P, Grabar A A, Stoika I M and Vysochanskii Y M, 2003. Fast near-infrared self-pumped phase conjugation with photorefractive $\mathrm{Sn}_{2} \mathrm{P}_{2} \mathrm{~S}_{6}$. J. Opt. Soc. Am. B. 20: 1241-1256.

8. Martynyuk-Lototska I Yu, Mys O G, Grabar A A, Stoika I M, Vysochanskii Yu M and Vlokh R O, 2008. Highly efficient acoustooptic diffraction in $\mathrm{Sn}_{2} \mathrm{P}_{2} \mathrm{~S}_{6}$ crystals. Appl. Opt. 47: 52-55.

9. Martynyuk-Lototska I, Mys O, Zapeka B, Grabar A and Vlokh R, 2010. Acoustic wave velocities and elastic properties of $\mathrm{Sn}_{2} \mathrm{P}_{2}\left(\mathrm{Se}_{0.28} \mathrm{~S}_{0.72}\right)_{6}$ solid solutions. Philos. Mag. 90: 43494359.

10. Mys O, Zapeka B, Martynyuk-Lototska I, Vlokh R, 2012. Elastic and acoustooptic properties of $\mathrm{Sn}_{2} \mathrm{P}_{2} \mathrm{~S}_{6}$ crystals: effect of ferroelastic phase transition. Opt. Mat. 35: 168-174.

11. Mys O, Martynyuk-Lototska I, Kostruba A M, Grabar A and Vlokh R, 2012. On the acoustooptic efficiency of $\mathrm{Pb}_{2} \mathrm{P}_{2} \mathrm{Se}_{6}$ crystals. Acoustic and thermal studies. Ukr. J. Phys. Opt. 13: 177-182.

Ukr. J. Phys. Opt. 2013, Volume 14, Issue 4 
12. Mys O, Martynyuk-Lototska I, Kostruba A M, Grabar A and Vlokh R, 2013. Efficient materials for spin-to-orbit angular momentum conversion using bending technique. Ukr.J.Phys.Opt. 14: $210-211$.

13. 13. Carpentier $\mathrm{C}$ and Nitsche R, 1974. Vapour growth and crystal data of the thio(seleno)hypodiphosphates $\mathrm{Sn}_{2} \mathrm{P}_{2} \mathrm{~S}_{6}, \mathrm{Sn}_{2} \mathrm{P}_{2} \mathrm{Se}_{6}, \mathrm{~Pb}_{2} \mathrm{P}_{2} \mathrm{~S}_{6}, \mathrm{~Pb}_{2} \mathrm{P}_{2} \mathrm{Se}_{6}$ and their mixed crystals. Mat. Res. Bull. 9: 401-410.

14. 14. Say A, Mys O, Grabar A, Vysochanskii Yu and Vlokh R, 2009. Thermal expansion of $\mathrm{Sn}_{2} \mathrm{P}_{2} \mathrm{~S}_{6}$ crystals. Phase Trans. 82: 531-540.

15. 15. Say A, Mys $\mathrm{O}$ and Vlokh R, 2010. Thermal expansion of the $\mathrm{Sn}_{2} \mathrm{P}_{2}\left(\mathrm{Se}_{0.28} \mathrm{~S}_{0.72}\right)_{6}$ solid solutions. Philos. Mag. 90: 3389-3400.

Mys O., Girnyk I., Grabar A., Martynyuk-Lototska I., Kostyrko M. and Vlokh R. 2013. Thermal expansion of $\mathrm{Pb}_{2} \mathrm{P}_{2} \mathrm{Se}_{6}$ crystals. Ukr.J.Phys.Opt. 14: 219 - 224.

Анотація. В роботі представлені результати дослідження коефіцієнтів термічного розширення кристалів $\mathrm{Pb}_{2} \mathrm{P}_{2} \mathrm{Se}_{6}$ в широкому температурному інтервалі. Компоненти тензора термічного розиирення визначені, як в кристалографічній системі координат так $i$ в системі координат, базованій на власних векторах тензора. Показано, щяо коефіцієнти тензора термічного розширення кристалів $\mathrm{Pb}_{2} \mathrm{P}_{2} \mathrm{Se}_{6}$ майже не залежать від температури, щьо створює передумови для застосування ичих кристалів. 